\title{
Use of two different approaches to the synthesis of nano zero valent iron for sediment remediation
}

\author{
Slijepcevıc N., Kerkez Dj.* ,Tomasevıc Pilıpovıc D., Becelıc-Tomın M., Dalmacıja B. and Krcmar D. \\ University of Novi Sad, Faculty of Sciences, Department for Chemistry, Biochemistry and Environmental Protection, Trg Dositeja \\ Obradovica 3, 21000 Novi Sad, Serbia
}

Received: 27/02/2018, Accepted: 26/09/2018, Available online: 26/09/2018

*to whom all correspondence should be addressed: e-mail: djurdja.kerkez@dh.uns.ac.rs

https://doi.org/10.30955/gnj.002649

\begin{abstract}
Heavy metals are one of the main pollutants of river, lake and canal sediments. Stabilization technology proved to be an effective method for solving this problem. Stabilization covers a wide range of remediation techniques that are used to transform waste into forms that will be less problematic for the environment. Stabilization of the Great Backi Canal sediment was carried out by using nanomaterials, namely nano zero-valent iron (nZVI). Two different approaches for the synthesis of nanomaterials were used, conventional and so-called "green" method. For conventional, borohydridemethod, nZVI was stabilized with native clay as porous material which proved to be very effective because of its specific surface area. Extract of oak leaves was used for green method which contains polyphenols as promising agents for the nZVI synthesis. Assessment of the treatment efficiency was performed by using semi-dynamic leaching test ANS 16.1. In order to stimulate leaching conditions, similar to those at the landfill, ANS 16.1 method was modified by using humic acid solution. These results showed that metals were successfully immobilized in the sediment.
\end{abstract}

Keywords: Heavy metals, nZVI, sediment, stabilization.

\section{Introduction}

Sediment that represents an essential component of a dynamic ecosystem often becomes contaminated with heavy metals from different effluents discharging into rivers, lakes and etc. The Great Backi Canal represents such an environment, as it is also called a "black point", with the amount of contamination of organic or inorganic origin. Sorption of heavy metals, as well as persistent, bioaccumulative and toxic substances in the sediment, create potential environmental risks both at the local and global levels (Tomasevic, 2013). A remediation technique called stabilization was showed as efficient solution for the removal of metals from the aquatic sediment, which involves the addition of a binder to immobilize heavy metals. Iron nanoparticles (nZVI) proved as an effective material/binder for immobilization. Two different approaches for the synthesis of nZVI were used, conventional and so-called "green" method. nZVI particles are small in size, but they have large specific surface area and great reactivity of surface sites. Conventional production of nano zero-valent iron includes the chemical reaction of $\mathrm{NaBH}_{4}$, as a reducing agent, with iron salts (Sun et al., 2006). However, nZVI nanoparticle, which were synthesized by this method, tend either to react with surrounding media or agglomerate into a chain-like structures, (Sun et al., 2007) resulting in significant loss of reactivity of surface area. Iron particles stability upon agglomeration can be enhanced by imparting electrostatic repulsion, using organic surfactants and different stabilizers, or by using of capping agents (Sun et al., 2007). A wide variety of stabilizers, like different porous material, have been proposed to modify nZVI particle surface characteristics (He and Zhao, 2005; Wang et al., 2014), which will prevent particle aggregation. More recently, kaolin-supported nZVI (Chen et al., 2012), bentonitesupported nZVI (Chen et al., 2011) and native clay-supported nZVI (Kerkez et al., 2014) have been used to reduce the extent of $n Z \mathrm{VI}$ aggregation. These indications suggest that implementing stabilized nZVI particles may represent an effective method for remediation of contaminated aquatic sediment. Nowdays so-called green method or green synthesis of iron nanoparticles has been developed recently as an alternative to this traditional method. Sodium borohydride, which is known for its toxicity, corrosiveness and flammability, is not used for green method (Hoag et al., 2009). This green method involves the fast reaction of aquatic extract of tea, tree or bush leaves, which contains polyphenols with iron salts. (Hoag et al., 2009; Machado et al., 2013). Metals can be reduced by polyphenols in oak leaves extract. They can act both as reducing and capping agents, thanks to high antioxidant capacity (Machado et al., 2013) that protects the iron nanoparticles from oxidation and also imparts steric stabilization against agglomeration/aggregation (Hoag et al., 2009). Polyphenols also contain molecules carrying alcoholic functional groups, which can be used for reduction as well as for stabilization of nano 
zero-valent iron (Nadagouda and Varma, 2008; Nadagouda et al., 2010). Proposed mechanism of synthesis of $\mathrm{Fe}^{2+}$ with polyphenols and other polyol compounds, can be also applied for the synthesis with $\mathrm{Fe}^{3+}$, which is given by Smuleac et al. (2011), and showed through this general reaction:

$$
\mathrm{nFe}^{2+}+2 \mathrm{Ar}-(\mathrm{OH}) \mathrm{n} \rightarrow \mathrm{nFe} \mathrm{O}^{0}+2 \mathrm{nAr}=\mathrm{O}+2 \mathrm{nH}^{+}
$$

Where $A r$ is the phenyl group and $n$ is the number of hydroxyl groups oxidized by $\mathrm{Fe}^{2+}$. This new green synthetic method is very simple to approach. It is environmentally friendly and can produce very stable quantities of nano zero-valent iron (Hoag et al., 2009).

Stabilised material can be used either for particular purpose, or it can be disposed on the landfills. Over time, the composition of landfill waste is changed, and a large part of this material is not easily biodegradable. Leaching is considereda long-term emission from landfills that are used for disposal of such material. In order to estimate leaching time and magnitude, different methods such as small tests are applied upon a large-scale field test. It is, therefore, reasonable to assume that if the conditions are closer to field ones, the results will be closer to the actual values for future emissions at the landfill. In order to

design the leaching tests that are reliable for long-term predictions, the most important is the knowledge of the factors affecting on that leaching. The basic division of leaching tests includes extraction and dynamic tests. Dynamic tests include continuous or occasional renewal of extracting agent in order to maintain a large difference in concentration between the solid and liquid phases. They provide information regarding to the kinetic, immobilization of contaminants and complex mechanisms in connection with the leaching.

The aim of this research was to stabilize and immobilize heavy metals, in this case copper and nickel, from freshwater canal sediment of The Great Backi Canal by two different approaches of nZVI particles synthesis. The tretament efficiency of this remediation technique was performed by semi-dynamic leaching test ANS 16.1 (ANS, 1986).

\section{Materials and methods}

\subsection{Preparation of clay supported $n Z$ VI particles}

The chemical composition of native clay from Kanjiza (Vojvodina, Serbia) was (wt\%): $\mathrm{SiO}_{2}(55.7 \%), \mathrm{Al}_{2} \mathrm{O}_{3}(14.9 \%)$, $\mathrm{Fe}_{2} \mathrm{O}_{3}(5.78 \%), \mathrm{MgO}(2.86 \%), \mathrm{CaO}(5.90 \%), \mathrm{K}_{2} \mathrm{O}(0.830 \%)$, $\mathrm{TiO}_{2}(0.800 \%)$ and loss of ignition $14.03 \%$.
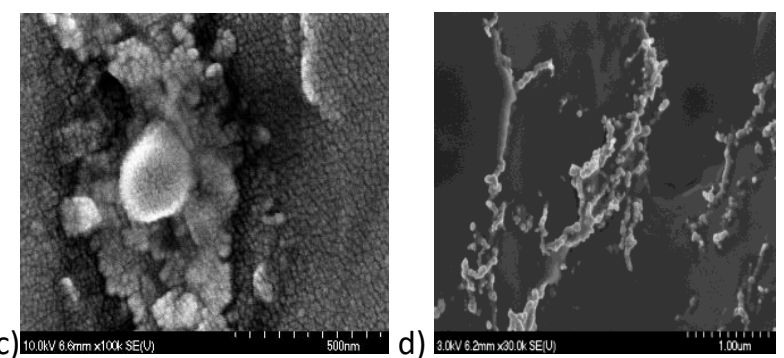

Figure 1. TEM and SEM images of OL-nZVI and NC-nZVI: a) TEM image of OL-nZVI, b) TEM image of NC-nZVI, c) SEM image of OL-nZVI, d) SEM image of NC-nZVI (Kerkez et al., 2014; Poguberovic et al., 2016)

NC-nZVI was prepared by using a conventional liquid-phase method, by the reduction of ferric iron byborohydride, in presence of native clay. Weight ratio of native clay and $\mathrm{nZVI}$ was 1:1. From the beginning to the end of process $\mathrm{N}_{2}$ gas was applied through the solution to prevent oxidization. The prepared NC-nZVI was refrigerated at $4{ }^{\circ} \mathrm{C}$. The preparation method is similar to the one in researches from Shi et al., 2011 and Tomašević et al., 2014.

\subsection{Preparation of green zero-valent iron nanoparticles}

Oak leaves were collected from Quercus pea trees, growing in the forest near the Danube river, at Novi Sad, Vojvodina, Serbia. The leaves were milled by using a kitchen chopper, then sieved by using a $2 \mathrm{~mm}$ sieve and pre-dried at $50{ }^{\circ} \mathrm{C}$ in an oven for $48 \mathrm{~h}$. The amount of $3.7 \mathrm{~g}$ of the oak leaves was measured and carried to a $300 \mathrm{~mL}$ Erlenmeyer flask, to which $100 \mathrm{~mL}$ of water was added. Then the flask was put in a shaker bath at $80{ }^{\circ} \mathrm{C}$ for $20 \mathrm{~min}$. The extraction procedure was given according to Machado et al. (2013). Extract of oak leaves was mixed with $0.1 \mathrm{M} \mathrm{Fe}($ III) solution
$\left(\mathrm{FeCl}_{3} \cdot 6 \mathrm{H}_{2} \mathrm{O}\right.$, Centrohem Serbia) in a volume ratio of 3:1. The presence of intense black colored precipitate was an indication of the Fe nanoparticles formation.

\subsection{Characterization of OL-nZVI and NC-nZVI}

Transmission electron microscopy (TEM; Philis CM 10) and scanning electron microscope (SEM) analyses (SEM; Hithchi S-4700 Type II) images were recorded to determine the morphology, size and nZVI particles distribution. Structural analysis was performed by using $77 \quad \mathrm{~K} \quad \mathrm{~N}_{2}$ adsorption-desorption isotherms by Autosorb iQ Surface Area Analyzer (Quantochrome Instruments, USA). The specific surface areas (SSA) of nanoparticles were measured by using the multi-point BET (Brunauer-Emmett-Teller) method. Mesopore volumes were derived from desorption isotherms by using BJH (Barrett-Joyner-Halenda) model and micropore volumes were calculated by using t-test method.

\subsection{Sediment collection and preparation}

Sediment samples were collected from the Great Backi Canal basin (Vojvodina, Serbia). Pseudo-total trace metal contents were assessed on sample triplicate after nitric 
acid digestion employing US EPA standard method (USEPA Method 3051a, 2007), and mean values were used. The obtained relative standard deviations (\%RSD) $(n=3)$ were below $10 \%$. Metal contents were determined by AAS (Perkin Elmer AAnalystTM 700) according to the standard procedure (USEPA Method 7010, 2007). According to the Serbian system, the class limits are defined for "standard sediment", with $10 \%$ organic matter and $25 \%$ clay. Metal concentrations of the sediment were first corrected to standard sediment based on correction formulas and then classified according to the Serbian national evaluation scheme. Finally, the overall sediment quality was establishedby using the "worst class" sediment parameters. According to Serbian regulation standards, the sediment is polluted with $\mathrm{Cu}$ (class 4), and $\mathrm{Ni}$ (class 3 ). In the third and fourth classes, sediments are of unacceptable quality and urgently require dredging, disposal in special storage reservoirs and, if possible, sediment cleanup measures. Samples were designated by the capital letter O for (OL-nZVI: oak nano zero-valent iron, and N for NC-nZVI: native clay nano zero-valent iron) followed by a number indicating the percent weight of the given attribute. The content of nanomaterial was expressed as percentage of the total solids weight. During the leaching test, 4 types of specimens were tested: 5\% OL-nZVI, 10\% OL-nZVI, 5\% NC-nZVI, and 10\% NC-nZVI. Samples were prepared in the form of monolithic cubes $[(3 \pm 0.1) \mathrm{cm}(3 \pm 0.1) \mathrm{cm}(3 \pm$ $0.1) \mathrm{cm}$ ] by compaction at an optimum water content, defined as the water content at which the maximum dry density is achieved for a given compactive effort. The compaction was performed according to ASTM D1557-00 procedure, and after 28 days subjected to semi-dynamic test ANS 16.1 (ANS 16.1, 1986).

\subsection{ANS 16.1 test}

The long-term leaching behavior of $\mathrm{Cu}, \mathrm{Ni}$, from treated sediment samples was evaluated byusing ANS method 16.1 (1986). A cumulative fraction of metals, leached after 90 days, was obtained by applying this test. A mathematical diffusion model based on the Fick's second law is used to evaluate the leaching rate as a function of time, and the leachability index which currently is used by Environment Canada (1991), presents an average of the negative logarithm of the effective diffusivity terms. According to ANS 16.1 test (1986), the liquid/solid ratio was $10 / 1\left(\mathrm{~kg}^{-1}\right)$ and collected leachate from defined time intervals were filtered through a 0.45 - $\mu \mathrm{m}$-pore-size membrane filter, andsubjected to AAS for concentrations of $\mathrm{Cu}$ and $\mathrm{Ni}$. In this study ANS 16.1. test was modified by humicacid (HA) solution (20 mg TOC $\mathrm{I}^{-1}$ ) as leachant, in order to mimic possible contidions similar those at the landfill environment.

\section{Results and discussion}

\subsection{Characterization of produced nanomaterials}

The TEM images presented in Figure 1 confirm the formation of nano zero-valent iron particles. Native claysupported nZVI particles were clearly distinct and well dispersed in the clay carriers, without aggregation.
The obtained particles are close to spherical, with grain size of $50 \mathrm{~nm}$ in diameter (Figure 1b). SEM images (Figure 1d) of NC-nZVI showed many nodular protrusions over the surface. They were spherical in shape, and were distributed throughout the surface of the native clay without noticeable agglomeration as the same observation was showed in Kerkez et al., 2014.

TEM images of OL-nZVI (Figure 1a) show that particles are spherical and non-agglomerated, with size within 10-30 nm, likethey were also showed in the research by Poguberović et al., 2016. SEM images also show spherical shape of nanoparticles, with no significant agglomeration, because polyphenols from oak leaves act both as dispersive and capping agents (Figure 1c).

The multi-point BET specific surface areas and BJH total pore volume of NC-nZVI and OL-nZVI were $9.6 \mathrm{~m}^{2} \mathrm{~g}^{-1}$, $0.080 \mathrm{~cm}^{3} \mathrm{~g}^{-1}$ and $1.45 \mathrm{~m}^{2} \mathrm{~g}^{-1}, 0.008 \mathrm{~cm}^{3} \mathrm{~g}^{-1}$, respectively. There was no presence of micropore in both synthesized nanomaterials. However, the SSA of OL-nZVI is smaller than NC-nZVI (synthesized utilizing chemical methods), (Chen et al., 2011), which is likely to occur due to the surface of OL-nZVI being enveloped in organic molecules, existing in tea extracts as it was showed in previous SEM images. BJH total pore volume of NC-nZVI is larger in comparison to green synthesized nanomaterial, which attests to the presence of mesopore formed by the intercalated Fe nanoparticles.

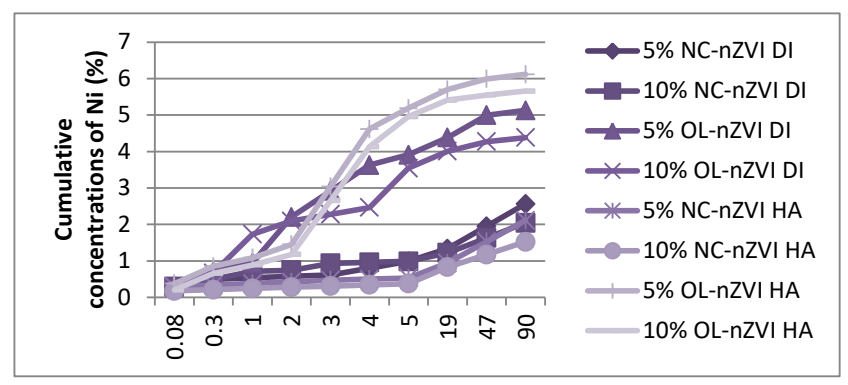

Figure 2. Cumulative leaching concentrations of $\mathrm{Ni}(\%)$

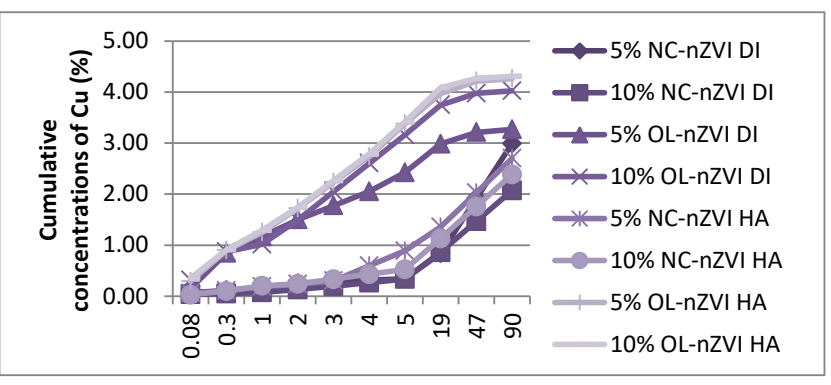

Figure 3. Cumulative leaching concentrations of $\mathrm{Cu}(\%)$

\subsection{Pseudo-total metal concentrations of untreated sediment sample}

Pseudo-total concentrations of $\mathrm{Cu}$ was $440.04 \pm 15 \mathrm{mg}$ $\mathrm{kg}^{-1}$ and $\mathrm{Ni} 111.02 \pm 7 \mathrm{mg} \mathrm{kg}^{-1}$. Mineral fraction of $<2 \mu \mathrm{m}$ was $15.08 \%$ of sediment dry weight, and the fraction of 2-63 $\mu \mathrm{m}$ ranged from 6.80 to $47.43 \%$ sediment dry weight (ISO 11277:2009). The content of organic matter in the sediment sample was $11.9 \%$ (NEN 5754:1994). 
Average initial moisture content of sediment samples was $72.5 \%$, so they were dried at $105{ }^{\circ} \mathrm{C}$ to constant mass and then mixed with $\mathrm{OL}$ and $\mathrm{NC}-\mathrm{nZVI}$ in different weight percentage.

\subsection{ANS 16.1 test}

Cumulative percentages of leached metals (Ni (Figure 2) and $\mathrm{Cu}$ (Figure 3) from the mixtures with sediment and synthesized $n Z V I$ by using the oak leaf extract (OL-nZVI) and by using native clay for supported nZVI (NC-nZVI) are presented as a function of leaching time. Cumulative percent of leach metals after 90 days in deionized water ranged for samples with OL-nZVI:

- from $0.26 \%$ to $4.02 \%$ for copper,

- from $0.26 \%$ to $5.13 \%$ for nickel,

and for samples with NC-nZVI:

- from $0.04 \%$ to $2.99 \%$ for copper

- from $0.29 \%$ to $2.56 \%$ for nickel.

Cumulative percent of leach metals after 90 days in humic acid ranged for samples with OL-nZVI:

- from $0.29 \%$ to $4.31 \%$ for copper,

- from $0.20 \%$ to $6.12 \%$ for nickel,

and for samples with NC-nZVI:

- from $0.03 \%$ to $2.70 \%$ for copper

- from $0.18 \%$ to $2.11 \%$ for nickel.

If the percentage of leached metals is observed as the criterion of the treatment efficiency, than treatment with OL-nZVI and NC-nZVI proved to be effective in the case of copper and nickel because leaching percentage slightly exceeded $6 \%$. The native clay which was used for stabilisation of $\mathrm{nZVI}$ in presence of humicacid behaved like chelating agent for heavy metal ions and caused lower metal mobility than in deionized water. Hizal and Apak (2006) presented that humic acid reacts on clay surfaces, not only with silanol and aluminol groups, but also with organic components in clay,by hydrogen bonds and Van der Waals' forces.

If the cumulative valueis compared with the national legislation ("Off. Gazette of RS", no. 56/2010), it can be concluded that all mixtures with OL-nZVI and NC-nZVI in terms of the concentration of $\mathrm{Cu}$ and $\mathrm{Ni}$ may be considered as non-hazardous waste, because leaching concentrations satisfy the values laid down in national legislation.

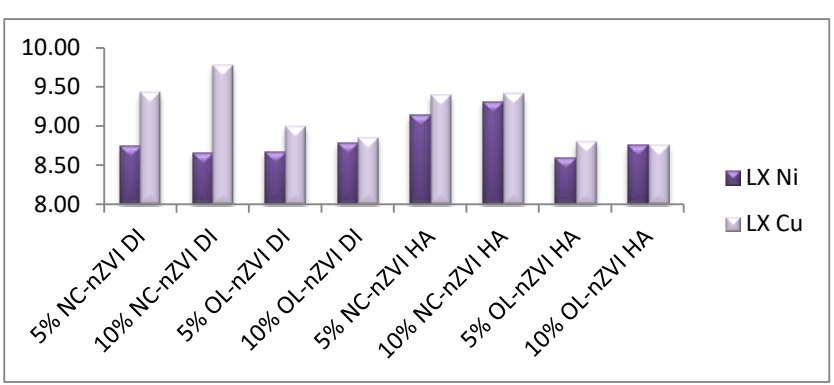

Figure 4.Mean leachability index (LX)
ANS 16.1 leaching model benefits Fick diffusion theory and provides a diffusion rate that can enable the evaluation of effectiveness from stabilization treatment (ANS, 1986; Dermatas and Meng, 2003; Dermatas et al., 2004; Moon et al., 2004; Moon and Dermatas, 2007) based on the determination of diffusion coefficients (De) and leaching index (LX). According to Nathwani and Phillips (1980), the diffusion coefficients of metals of the mixture generally range from values for highly mobile metals, about E-05 $\mathrm{cm}^{2} \mathrm{~s}^{-1}$ to $\mathrm{E}-15 \mathrm{~cm}^{2} \mathrm{~s}^{-1}$ (practically immobilized metals in the stabilized compositions).

Mean values of diffusion coefficients (De) generally ranged:

- from $2.59 \mathrm{E}-09 \mathrm{~cm}^{2} \mathrm{~s}^{-1}$ to $6.50 \mathrm{E}-09 \mathrm{~cm}^{2} \mathrm{~s}^{-1}$ in the mixtures with OL-nZVI in deionized water

- from $1.95 \mathrm{E}-09 \mathrm{~cm}^{2} \mathrm{~s}^{-1}$ to $3.74 \mathrm{E}-09 \mathrm{~cm}^{2} \mathrm{~s}^{-1}$ in the mixtures with NC-nZVI in deionized water

- from $4.16 \mathrm{E}-09 \mathrm{~cm}^{2} \mathrm{~s}^{-1}$ to $9.22 \mathrm{E}-09 \mathrm{~cm}^{2} \mathrm{~s}^{-1}$ in the mixtures with OL-nZVI inhumic acid

- from $1.32 \mathrm{E}-09 \mathrm{~cm}^{2} \mathrm{~s}^{-1}$ to $2.80 \mathrm{E}-09 \mathrm{~cm}^{2} \mathrm{~s}^{-1}$ in the mixtures with NC-nZVI in humic acid

According to diffusion coefficients, it can be concluded that copper and nickel are partly mobile in all mixtures of sediment and nanomaterials.

According to the Canadian Agency for Environmental Protection (Environment Canada, 1991) LX values can be taken as a criterion for the use and disposal of the treated waste.

If the efficacy of the treatment is observed in terms of the $\mathrm{LX}$ value, the treatment can be considered to be partially successful because in all mixtures of OL-nZVI and NC-nZVI, $\mathrm{LX}$ values for $\mathrm{Ni}$ ranged between 8 and 9, only mixtures with addition of $5 \%$ and $10 \%$ of NC-nZVI were slighty above value 9 , therefore, these mixtures can be safely disposed of on a landfill. (Figure 4). For copper, LX values for mixtures with NC-nZVI were higher than 9, and can be considered for "controlled utilization", while for OL-nZVI this LX values were below 8 , and can be safely disposed of on a landfill. As the worst value defines the criteria for the use of waste, these mixtures can be safely disposed of on isolated or sanitary landfills.

The external (hydro) oxide layer of Fe nanoparticle can act as an effective adsorbent for various contaminants including metals. The specific removal mechanisms were involved in treatment of heavy metal contamination with $n Z V I$ depend on the standard redox potential $\left(E^{0}\right)$ of the metal contaminant. Metals with a more positive $\mathrm{E}^{0}$ of $\mathrm{Fe}^{0}$ (for example, $\mathrm{Cu}$ ) were preferentially removed by reduction and precipitation (Li and Zhang, 2007). Metals with a little more positive $\mathrm{E}^{0}$ than $\mathrm{Fe}^{0}$, (for example, $\mathrm{Ni}$ ) can be removed both as by reduction and adsorption. Oxidation and co-precipitation of iron oxide are other possible mechanisms. They depend on the prevailing geochemical conditions, such as $\mathrm{pH}$ value, initial concentration and speciation of metals. Passivation of $\mathrm{nZVI}$ as well as difference of $\mathrm{pH}$ values can reduce or decrease this removal of heavy metals from sediment, 
thus the oxidation of nZVI. So it can be concluded that polyphenols in oak leaf prevent oxidation of nZVI particles and increase the immobilization of metals in sediment, as well as reactivity of OL-nZVI. Clay also play an important role in the environment because they are natural "sponge " of pollutants, binding their anions or cations by ion exchange or adsorption. There is a chemical change and substitution with other cations when crystal of clay is suspended in water. In addition, ions may also be adsorbed on the clay crystal edges and be exchanged with other ions in water/soil (Patel et al., 2007). This clay mineral used for supported nZVI particles behaved like a chelating agent for heavy metals and also for nZVI particles, which is in good correlation with BET specific surface area, previously mentioned.

Although a similar mechanism for the removal of heavy metals was observed with the use of both nanomaterials. However, NC-nZVI was slightly more effective, thanks to the higher specific surface area indicated by the application of the BET method, and in agreement that clay supported nanoparticles act as a combination of reduction by $\mathrm{nZVI}$, and adsorption by appropriate clay, unlike OL-nZVI. The larger surface area can contribute to more uniform distribution of $\mathrm{nZVI}$ particles on appropriate clays.

Therefore, these two nanomaterials generally have showed similar results and can be efficiently used for a treatment of heavy metals with a small amount added in the sediment. However, this is very important for using a new green method which can be applied for sediment remediation, avoiding the use of toxic chemicals, such as $\mathrm{NaBH}_{4}$. Fallen leaves, usually considered as waste withought any added value, in this way can be useful and have economic purpose.

\section{Conclusion}

This research investigates nanotechnology regarding stabilization of heavy metals in contaminated aquatic sediments. To reduce the leachability of copper and nickel in sediment, nZVI supported with native clay, and nZVI synthesized using oak leaf extract were used as stabilization agents. Surface coating of native clay and polyphenols from oak leaves prevented the nZVI particles from agglomerating or oxidation, enhancing their mobility and reactivity in sediment media. These applied nanomaterials proved to be effective in immobilization of copper and nickel in the canal sediment. Further research should be focused on the toxicity of these nanomaterials and also on more detailed investigation of their bioavailability, then on determining the fraction of metals with different bonding forces etc. Data showed that for the sediment quality assessment a variety of standard methods must be used, in order to safely assess the risk to the environment.

\section{Acknowledgments}

This work has been produced with the financial assistance from The Ministry of Education, Science and Technological
Development of the Republic of Serbia (Project Numbers III43005 and TR37004).

\section{References}

ANS (American National Standard) ANSI/ANS 16.1 (1986), American National Standard for the Measurement of the Leachability of Solidified Low Level Radioactive Wastes by Short-term Tests Procedures. American National Standards Institute, New York.

ASTM D1557-00 Standard test method for laboratory compaction characteristics of soil using modified effort American Society for Testing Materials. Annual book of ASTM standards: ASTMD1557-91, vol 4.08. ASTM, Philadelphia.

Chen Z., Cheng Y., Chen Z., Megharaj M. and Naidu R. (2012), Kaolin-supported nanoscale zero-valent iron for removing cationic dye-crystal violet in aqueous solution, Journal of Nanoparticle Research, 14, 899.

Chen Z., Jin X., Chen Z., Megharaj M. and Naidu R. (2011), Removal of methyl orange from aqueous solution using bentonite-supported nanoscale zero-valent iron, Journal of Colloid and Interface Science, 363, 601-607.

Dermatas D. and Meng X. (2003), Utilisation of fly ash for stabilization/solidification of heavy metal contaminated soils, Engineering Geology, 70, 377-394.

Dermatas D., Moon D., Menounou N., Meng X. and Hires R. (2004), An evaluation of arsenic release from monolithic solids using a modified semi-dynamic leaching test, Journal of Hazardous Materials, 116, 25-38.

Environment Canada, Proposed Evaluation Protocol for CementBased Solidified Wastes (1991), Environmental Protection Series. Report No. EPS 3/HA/9.

He F. and Zhao D. (2005), Preparation and characterization of a new class of starch stabilized bimetallic nanoparticles for degradation of chlorinated hydrocarbons in water, Environmental Science and Technology, 39, 3314-3320.

Hizal J. and Apak R. (2006), Modeling of cadmium (II) adsorption on kaolinite-based clays in the presence and absence of humic acid, Applied Clay Science, 32, 232-244.

Hoag G.E., Collins J.B., Holcomb J.L., Hoag J.R., Nadagouda M.N. and Varma R.S. (2009), Degradation of bromothymol blue by 'greener' nano scale zero-valent iron synthesized using tea polyphenols, Journal of Materials Chemistry, 19, 8671-8677.

ISO 11277:2009 Soil quality-determination of particle size distribution in mineral soil material-method by sieving and sedimentation.

Kerkez D.J, Tomašević D., Kozma G., Bečelić-Tomin M., Prica M., Rončević S., Kukovecz A., Dalmacija B. and Konya Z. (2014), Three different clay-supported nanoscale zero-valent iron materials for industrial azo dye degradation: a comparative study, Journal of the Taiwan Institute of Chemical Engineers, 45, 2451-2461.

Li X.Q. and Zhang W.X. (2007), Sequestration of metal cations with zero valent iron nanoparticles-a study with high resolution X-ray photoelectron spectroscopy (HR-XPS), Journal of Physical Chemistry C, 111, 6939-6946.

Machado S., Pinto S.L., Grosso J.P., Nouws H.P.A., Albergaria J.T. and Delerue-Matos C. (2013), Green production of zero-valent iron nanoparticles using tree leaf extracts, Science of the Total Environment, 445-446, 1-8. 
Moon D.H. and Dermatas D. (2007), Arsenic and lead release from fly ash stabilized/solidified soils under modified semi-dynamic leaching conditions, Journal of Hazardous Materials, 141, 388-394.

Moon D.H., Dermatas D. and Menounou N. (2004), Arsenic immobilization by calcium-arsenic precipitates in lime treated soils, Science of the Total Environment, 330, 171-185.

Nadagouda M.N., Casle A.B., Murdock R.C., Hussain S.M. and Varma R.S. (2010), In vitro biocompatibility of nanoscale zero valent iron particles (nZVI) synthesized using tea polyphenols, Green Chemistry, 12, 114-122.

Nadagouda M.N. and Varma R.S. (2008), Green synthesis of silver and palladium nanoparticles at room temperature using coffee and tea extract, Green Chemistry, 10, 859-862.

Nathwani J.S. and Phillips C.R. (1980), Leachability of Ra-226 from uranium mill tailings consolidated with naturally occurring materials and/or cement: analysis based on mass transport equation, Water, Air, \& Soil Pollution, 14, 389-402.

NEN 5754:1994 Determination of organic matter content in soil as loss-on-ignition.

Official Gazzete (2010), Ministry of Energy, Development and the Environment, Regulation on categories, testing and classification of waste. The Official Gazette 56/2010.

Patel A.D., Stamatakis E., Davis E. andd Friedheim J. (2007), High performance water based drilling fluids and method of use. US Patent 7, assigned to M-I L.L.C. (Houston, TX), July 31 2007.

Poguberović S., Krčmar D., Maletić S., Konya Z., Pilipović Tomašević D., Kerkez D.J. and Rončević S. (2016), Removal of $\mathrm{As}(\mathrm{III})$ and $\mathrm{Cr}(\mathrm{VI})$ from aqueous solutions using "green" zero-valent iron nanoparticles produced by oak, mulberry and cherry leaf extracts, Ecological Engineering, 90, 42-49.

Shi L., Lin Y., Zhang X. and Chen Z. (2011), Synthesis, characterization and kinetics of bentonite supported $n Z V I$ for the removal of $\mathrm{Cr}(\mathrm{VI})$ from aqueous solution, Chemical Engineering Journal, 171, 612-617.

Smuleac V., Varma R., Sikdar S. and Bhattacharyya D. (2011), Green synthesis of Fe and Fe/Pd bimetallic nanoparticles in membranes for reductive degradation of chlorinated organics, Journal of Membrane Science, 379, 131-137.

Sun Y.P., Li X.Q., Cao J.S., Zhang W.X. and Wang H.P. (2006), Characterization of zero-valent iron nanoparticles, Advances in Colloid and Interface Science, 120, 47-56.

Sun Y.-P., Li X.-Q., Zhang W.-X. and Wang H.P. (2007), A method for the preparation of stable dispersion of zero -valent iron nanoparticles, Colloids and Surfaces, A 308, 60-66.

Tomašević D. (2013), Application of stabilized nano zero valent iron and commercial immobilisation agents for remediation of sediment contaminated with toxic metals, PhD, Faculty of Sciences, and University of Novi Sad.

Tomašević D., Kozma G., Kerkez Dj.,Dalmacija B., Dalmacija M., Bečelić-Tomin M., Kukovecz A., Konya Z. and Rončević S. (2014), Toxic metal immobilization in contaminated sediment using bentonite- and kaolinite-supported nano zero-valent iron, Journal of Nanoparticle Research, 16, 2548.

USEPA Method 3051a (2007), Microwave assisted acid digestion of sediments, sludges, soils and, Revision 1.

USEPA Method 7010 (2007), Graphite furnace absorption spectrophotometry, Revision 0.
Wang X., Yang J. and Zhu M. (2014), Effects of PMMA/anisole hybrid coatings on discoloration performance of nano zerovalent iron toward organic dyes, Journal of the Taiwan Institute of Chemical Engineers, 45, 937-946. 